\title{
FABRICATION OF AN EXPERIMENTAL SETUP TO ANALYSE THE THERMODYNAMIC PROPRIETY OF WATER
}

\author{
Rahul Patel $^{1}$, Ramji Tripathi ${ }^{2}$, Sukhdev Gangwar ${ }^{3}$ \\ ${ }^{1}$ Assistant Professor, Mechanical Engineering Department of Chandra Shekhar Azad University of Agriculture and \\ Technology, Etawah (Campus), UP - India \\ ${ }^{2}$ Assistant Professor, Mechanical Engineering Department of Chandra Shekhar Azad University of Agriculture and \\ Technology, Etawah (Campus), UP - India \\ ${ }^{3}$ Department of Mechanical Engineering, Chandra Shekhar Azad University of Agriculture and Technology, Etawah \\ (Campus), UP - India
}

\begin{abstract}
An experimental setup was made to analyse some of thermodynamic properties of water. In these setup two pressure cookers was used. They were connected with a brass pipe having a gateway i.e., throttling valve in it. There was a pressure gauge and a temperature gauge fixed on the cap of each pressure cooker. A flow meter connected to brass pipe by poly urethane pipe was used to measure the volume flow rate of water vapour. Steam was generated in one of the pressure cooker by boiling water and second had left empty. Now generated steam was passes through brass pipe having gateway towards second pressure cooker. In this way, all the required reading of each measuring instrument was taken by this experimental setup. Thus all the thermodynamic properties of water like Joule-Thomson curve, $P$-V, $T$-s and h-s diagrams were studying by this setup.
\end{abstract}

Keywords- Pressure cookers, throttling device, free expansion, Joule-Kelvin effect, $P$-V, $T$-s and P-h diagrams $* * *$

\section{INTRODUCTION}

Thermodynamics is a branch of science that deals with energy, which is essential for sustenance of life. Thermodynamics is an essential part of engineering curricula and it has a broad application area. The study of thermodynamics is based on two general laws of nature that is the first and second law of thermodynamics.

This Experimental setup is very helpful for analysing the thermodynamics because with the help of this setup we can practically analyse and prove the fundamental laws of thermodynamics viz. second law of thermodynamics and throttling process. With the help of data obtained from this setup we can draw several diagrams as P-V, T-s and h-s diagrams, Joule-Thomson curve etc.

With the help of this experimental setup the analysis of thermodynamic properties of steam as $\mathrm{P}, \mathrm{T}, \mathrm{V}, \mathrm{S}$ etc. and to sketch their respective $\mathrm{P}-\mathrm{V}, \mathrm{T}-\mathrm{s}$ and $\mathrm{h}-\mathrm{s}$ diagrams can be easily done. In this experimental setup several components are used. These are listed as:

\subsection{Brass Pipe}

To connect the two pressure cookers with each other, a brass pipe is used. This also forms a throttling device with gateway.

\subsection{Gateway}

Gateway or throttling valve is a valve which produces restriction to flow the fluid through it. It is a constricted passage, like a partially opened valve, an orifice or a porous plug. Due to this obstruction there is an appreciable drop in pressure and the flow is said to be throttled. The gateway used in this project, is made of gun metal.

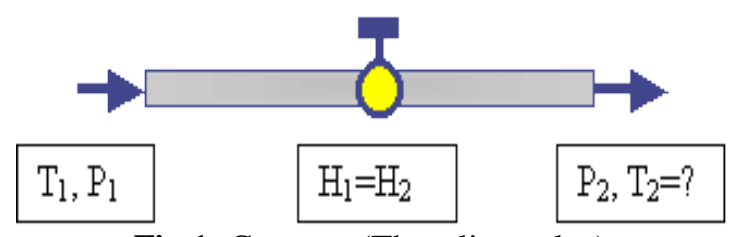

Fig 1: Gateway (Throttling valve)

\subsection{Temperature Gauge}

There are two temperature Gauges to measure the temperature of steam in each pressure cooker both are of range 0 to $150^{\circ} \mathrm{C}$. These are analogue bimetallic thermometers.

\subsection{Pressure Gauge}

Two Pressure gauges fitted in this experimental setup to measure the pressure of steam inside of each pressure cooker. Both gauges are of same range of 0 to 30 bar. These are analogue and mechanically operated gauges.

\subsection{Flow Meter}

A flow meter is an instrument used to measure linear, nonlinear, mass or volumetric flow rate of a liquid or a gas. In this setup, a flow meter using for measuring discharge of steam in litre per minute from 0 to 25 LPM. 


\subsection{Polyurethane Pipe}

Polyurethane pipe has been produced for many years in an extruded thermoplastic form however the production of thermoses polyurethane has been limited. Very durable, wide range of properties, non-abrasive and wear characteristic of polyurethane is allowing its use in many applications.

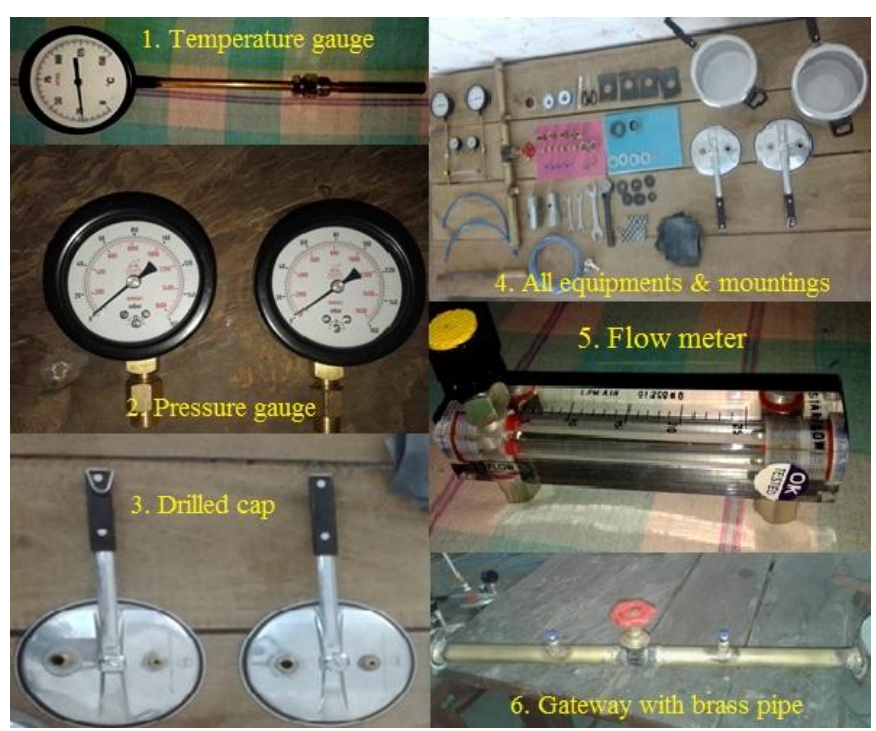

Fig 2: Components used in experimental setup

\section{FABRICATION OF EXPERIMENTAL SETUP}

To complete the experimental setup first of all base of the setup is prepared and after that all other equipment's are fixed. Experimental setup is made with frame which consists of all required equipment's fitted with following methods:

\subsection{Frame}

Frame is the basic requirement which provides support to the experimental setup. It may also be called as stand for this setup. It carries a stove with a gas burner on which whole assembled experimental setup is put for working.

Dimensions of the frame are $57 \times 34 \times 57$ inches, with one door at front and two windows in sides. Both the door and the windows are covered with transparent fibre sheet. This frame carries rollers to make it movable.

\subsection{Drilling on the Caps of Pressure Cookers}

To mount the temperature gauges and pressure gauge on the each cap of pressure cookers two holes of diameter $18 \mathrm{~mm}$ and $16 \mathrm{~mm}$ respectively are required. This is done by drilling on each cap with the help of drill machine.

\subsection{Drilling on the Side Wall of Pressure Cookers}

To connect the pressure cookers to each other with brass pipe hole of $38 \mathrm{~mm}$ diameter on the side wall of each pressure cookers are required. This is also done by drilling processes with the help of drill machine.

\subsection{Drilling on Brass Pipe}

To mount the fittings on the brass pipe to connect it with flowmeter with polyurethane pipe two holes of diameter with $16 \mathrm{~mm}$ each are required on both side of gateway valve.

\subsection{Threads Cutting}

Since the melting point of aliminium is lower than that of brass, pressure cookers and brass pipe cannot be welded. So use of nut and bolt assembly is more approprate. For this manufacturing of two reduce parts having external threads 32 $\mathrm{mm}$ and two chuck nuts having internal threads is done to tight the brass pipe with cookers.

\subsection{Welding on Brass Pipe}

Welding of the gateway valve and other mountings on brass pipe is done with oxy-accetelyne welding because gateway valve is made of gun metal and other mounting are made of brass. Thin mild steel washer with reduce part is also welded in brass pipe so that there will no leakage of steam from pressure cookers.

\subsection{Fitting Work on Caps}

Thermal gauge and pressure gauge are fitted on each pressure cooker cap in holes of $18 \mathrm{~mm}$ and $16 \mathrm{~mm}$ diameters repectively with the help of male-female connecters which have the external threads. Washers and Nuts are used to tightened these. Gaskits, teflon tape and anabond gaskit maker solution are used to make leak proof so that there will be no steam leakage.

\section{WORKING PROCEDURE}

Working procedure of the experimental setup is explained in six sections as-

\subsection{Procedure to Analyse Throttling Process and}

\section{Joule-Kelvin Effect}

A steam is made to undergo continuous throttling process by a valve. The pressure and temperature of the steam in the insulated pipe upstream and downstream of the valve are measured with suitable pressure gauge and temperature gauge. Let $\mathrm{P}_{\mathrm{i}}$ and $\mathrm{P}_{\mathrm{f}}$ be the arbitrarily chosen pressure and temperature before throttling and let them kept constant. By operating the valve manually, the steam is throttled successively to different pressure and temperature $\mathrm{P}_{\mathrm{fl}}, \mathrm{T}_{\mathrm{fl}}$; $\mathrm{P}_{\mathrm{f} 2}, \mathrm{~T}_{\mathrm{f} 2}$; and soon. These are then plotted on the T-P coordinates. All the points represent equilibrium states of some constant mass of steam, at which the steam has the same enthalpy.

$$
\mathbf{h}_{\mathbf{i}}=\mathbf{h}_{\mathbf{f}}
$$

The curve passing through all these points is an isenthalpic curve. This graph is not the graph of a throttling process, but the graph passing through the points of equal enthalpy. 


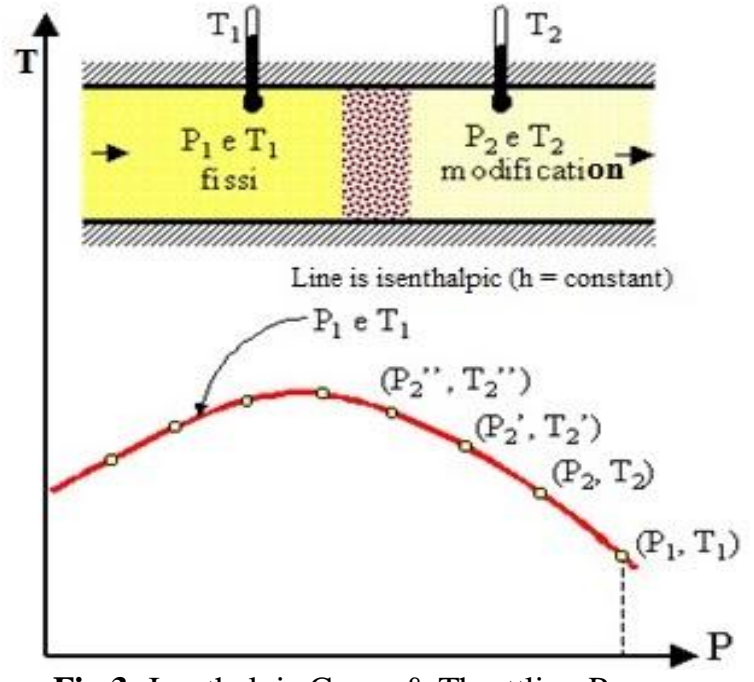

Fig 3: Isenthalpic Curve \& Throttling Process

The initial temperature and pressure of the steam before throttling are then set to new values and by throttling to different states, a family an isenthalpic is obtained for the steam. The curve passing through the maximum of these isenthalpes is called the inversion curve.

The numerical value of the slope of an isenthalpe on a T-P diagram at any point is called the Joule-Kelvin coefficient and is denoted by $\mu_{\mathrm{JT}}$.

Thus the locus of all points at which $\mu_{\mathrm{JT}}$ is zero is the inversion curve. The region inside the inversion $\mu_{\mathrm{JT}}$ is positive is called the cooling region and the region outside where $\mu_{\mathrm{JT}}$ is negative is called the heating region.

$$
\begin{gathered}
\boldsymbol{\mu}_{\mathbf{J T}}=\left(\frac{\boldsymbol{\delta} \mathbf{T}}{\boldsymbol{\delta} \mathbf{P}}\right)_{\mathbf{h}=\text { cons. }} \\
\mu_{\mathrm{JT}}=\left\{\begin{array}{l}
<0 \text { temperature increases } \\
=0 \text { temperature remains constant } \\
>0 \text { temperature decreases }
\end{array}\right.
\end{gathered}
$$

Thus there is no change in temperature when an ideal gas made to undergo a Joule-Kelvin expansion for achieving the effect of cooling by Joule-Kelvin expansion, the initial temperature of the steam must be below the point where the inversion curve intersects the maximum inversion temperature.

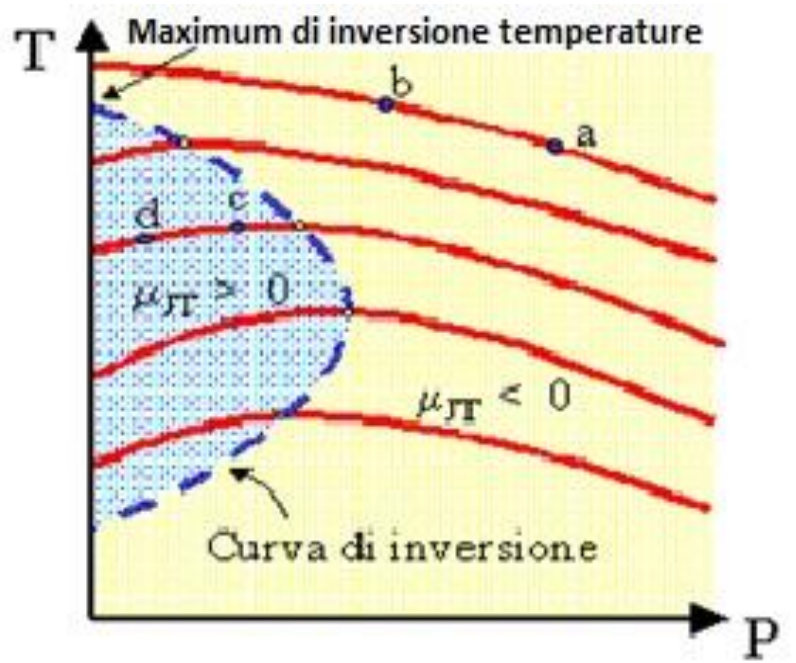

Fig 4: Isenthalpic Curves and Inversion Curve

\subsection{Procedure to Analyse P-V Diagram}

To analyse and draw the P-V diagram with the help of this experimental setup one pressure cooker unit and rota-meter are required. There is no requirement of second pressure cooker unit.

At starting the rota-meter and throttling valve are completely closed. Sufficient water has been taken in the pressure cooker and heats it until the pressure of steam in pressure cooker reach 15 bar where dead weight safety valve lifts. Now stop the heating pressure cooker. Gradually opening of the control valve of rota-meter shift the position of points and reading of both the pressure gauge and the rota-meter want to be noted down. From these reading P-V diagram can be draw.

\subsection{Procedure to Analyse P-T Diagram}

To analyse and draw the P-T diagram with the help of the experimental setup only one pressure cooker unit is used. Here gateway and control valve of rota-meter is to be closed. As water starts boiling there will be fluctuation on the dials of both pressure gauge and temperature gauge. Reading of pressure and corresponding temperature are to be note down and P-T diagram can be drawn.

\subsection{Procedure to Analyse T-V Diagram}

To analyse and draw the P-V diagram with the help of the experimental setup only one pressure cooker unit and rota meter are required.

At starting the rota meter and throttling valve are completely closed. Sufficient water has been taken in the pressure cooker and heats it until the pressure of steam in pressure cooker reach 15 bar where dead weight safety valve lifts. Gradually opening of the control valve of rota meter shifts the position of points and reading of both the temperature gauge and the rota meter want to be noted down. From these reading T-V diagram can be draw. 


\subsection{Procedure to Analyse Free Expansion}

To analyse the free expansion process with the help of this experimental setup both throttling valve and control valve of rota-meter are kept closed. Now generate the steam in first pressure cooker unit and kept its temperature and pressure constant $\mathrm{T}_{\mathrm{i}}, \mathrm{P}_{\mathrm{i}}$ arbitrary. Now suddenly opening of the gateway valve allow the steam pass towards second pressure cooker unit. Initially its temperature decreases to temperature say, $\mathrm{T}_{\text {int }}$ but after a very short time, steam temperature increases and reaches its final temperature which is equal to temperature of pressure cooker unit i.e. $T_{i}=T_{f}$. This increase in temperature is due to friction between wall of pipe and molecules of steam. In this way, note down readings of $T_{i}, T_{f}$ at different initial condition and make a table and draw the curve with dotted line because it is an irreversible process.

\section{RESULT \& ANALYSIS}

This setup is very useful in having practical approach in thermodynamics. Many experiments on this setup have done and the readings are notted down of pressure, temperature and volume. After these other corresponding characteristics are find out like enthalpy, Joule Kelvin Coefficient, drawn P$\mathrm{T}, \mathrm{P}-\mathrm{V}$ and $\mathrm{T}-\mathrm{V}$ diagrams.

\subsection{Analysis of Throttling Process \& Joule-Kelvin Effect}

To analyze throttling process and Joule-Kelvin Effect, JouleKelvin curve had drawn and the Joule-Kelvin coefficient $\left(\mu_{\Gamma}\right)$ also calculated on each point of each isenthalpe and draw the 0inversion curve where the value of $\mu_{\mathrm{T}}$ is zero. The region inside the inversion for which $\mu_{\Gamma}$ is positive is cooling region and the region for which $\mu_{\Gamma}$ is negative is heating region. The coordinates of joule kelvin curve enlisted in table- 1 .

Table 1: Coordinates of Joule-Kelvin Curves

\begin{tabular}{|c|c|c|c|c|c|}
\hline \multicolumn{2}{|c|}{ Isenthalpe 1 } & \multicolumn{2}{|c|}{ Isenthalpe 2 } & \multicolumn{2}{c|}{ Isenthalpe 3 } \\
\hline Pressure(bar) & Temperature $\left.^{\mathbf{0}}{ }^{\mathbf{C}} \mathbf{C}\right)$ & Pressure(bar) & Temperature $\left({ }^{\mathbf{O}} \mathbf{C}\right)$ & Pressure(bar) & Temperature $\left({ }^{\mathbf{O}} \mathbf{C}\right)$ \\
\hline 15.0 & 050 & 14.0 & 070 & 14.0 & 090 \\
\hline 14.5 & 055 & 13.5 & 075 & 13.0 & 100 \\
\hline 14.0 & 060 & 13.0 & 080 & 12.5 & 105 \\
\hline 13.5 & 065 & 12.5 & 085 & 12.0 & 110 \\
\hline 13.0 & 070 & 12.0 & 090 & 11.5 & 115 \\
\hline $12 . .5$ & 075 & 11.5 & 095 & 11.0 & 117 \\
\hline 12.0 & 080 & 11.0 & 097 & 10.5 & 120 \\
\hline 11.5 & 085 & 10.5 & 100 & 09.5 & 125 \\
\hline 11.0 & 087 & 09.5 & 105 & 08.5 & 128 \\
\hline 10.5 & 090 & 08.5 & 108 & 08.0 & 130 \\
\hline 09.5 & 095 & 08.0 & 112 & 07.0 & 135 \\
\hline 08.5 & 098 & 07.0 & 112 & 06.0 & 135 \\
\hline 08.0 & 100 & 06.0 & 112 & 05.0 & 135 \\
\hline 07.0 & 100 & 05.0 & 112 & 04.0 & 135 \\
\hline 06.0 & 100 & 04.0 & 110 & 03.0 & 130 \\
\hline 05.0 & 095 & 03.0 & 107 & 02.5 & 125 \\
\hline 04.0 & 090 & 02.5 & 102 & 02.0 & 120 \\
\hline 03.0 & 080 & 02.0 & 097 & 01.5 & 115 \\
\hline 02.0 & 070 & 01.5 & 090 & 01.0 & 110 \\
\hline 01.0 & 060 & 01.0 & 080 & 00.5 & 100 \\
\hline 00.0 & 050 & 00.0 & 070 & 00.0 & 090 \\
\hline
\end{tabular}

Calculated value of Joule-Kelvin coefficients are enlisted in following tables:

Table 2: Joule-Kelvin Coefficients for isenthalpe 1

\begin{tabular}{|c|c|c|c|c|c|c|c|}
\hline $\mathbf{T}_{\mathbf{1}}$ & $\mathbf{T}_{\mathbf{2}}$ & $\mathbf{P}_{\mathbf{1}}$ & $\mathbf{P}_{\mathbf{2}}$ & $\boldsymbol{\partial} \mathbf{T}=\mathbf{T}_{\mathbf{2}} \mathbf{T}_{\mathbf{1}}$ & $\partial \mathbf{P}=\mathbf{P}_{\mathbf{2}}-\mathbf{P}_{\mathbf{1}}$ & $\tilde{\partial T} / \partial \mathbf{P}=\boldsymbol{\mu}_{\boldsymbol{T}}$ & $\mathbf{E f f e c t}$ \\
\hline 070 & 080 & 02 & 03.0 & 10 & 01 & $10>0$ & Cooling \\
\hline 090 & 095 & 04 & 05.0 & 05 & 01 & $5>0$ & Cooling \\
\hline 050 & 060 & 00 & 01.0 & 10 & 01 & $10>0$ & Cooling \\
\hline 100 & 100 & 07 & 08.0 & 00 & 01 & 0 & Inversion \\
\hline 098 & 095 & 08 & 08.5 & -3.0 & 0.5 & $-6<0$ & Heating \\
\hline 095 & 090 & 9.5 & 10.5 & -5.0 & 01 & $-5<0$ & Heating \\
\hline 087 & 085 & 11 & 11.5 & -2.0 & 0.5 & $-4<0$ & Heating \\
\hline
\end{tabular}


Table 3: Joule-Kelvin Coefficients for isenthalpe 2

\begin{tabular}{|c|c|c|c|c|c|c|c|}
\hline $\mathbf{T}_{1}$ & $\mathbf{T}_{2}$ & $\mathbf{P}_{1}$ & $\mathbf{P}_{2}$ & $\partial \mathbf{T}=\mathrm{T}_{2}-\mathbf{T}_{1}$ & $\partial \mathbf{P}=\mathbf{P}_{2}-\mathbf{P}_{1}$ & $\partial \mathbf{T} / \partial \mathbf{P}=\mu_{\mathrm{JT}}$ & Effect \\
\hline 090 & 097 & 01.5 & 02 & 07 & 0.5 & $14>0$ & Cooling \\
\hline 102 & 107 & 02.5 & 03 & 05 & 0.5 & $10>0$ & Cooling \\
\hline 070 & 080 & 00.0 & 01 & 10 & 1.0 & $10>0$ & Cooling \\
\hline 112 & 112 & 07.0 & 08 & 0.0 & 1.0 & 0 & Inversion \\
\hline 108 & 105 & 08.5 & 9.5 & -3.0 & 1.0 & $-03<0$ & Heating \\
\hline 100 & 097 & 10.5 & 11 & -3.0 & 0.5 & $-06<0$ & Heating \\
\hline 075 & 070 & 13.5 & 14 & -5.0 & 0.5 & $-10<0$ & Heating \\
\hline
\end{tabular}

Table 4: Joule-Kelvin Coefficients for isenthalpe 3

\begin{tabular}{|c|c|c|c|c|c|c|c|}
\hline $\mathbf{T}_{1}$ & $\mathbf{T}_{2}$ & $\mathbf{P}_{1}$ & $\mathbf{P}_{2}$ & $\partial \mathbf{T}=\mathrm{T}_{2}-\mathbf{T}_{1}$ & $\partial \mathbf{P}=\mathbf{P}_{2}-\mathbf{P}_{1}$ & $\partial \mathbf{T} / \partial \mathbf{P}=\mu_{\mathrm{JT}}$ & Effect \\
\hline 100 & 110 & 00.5 & 01.0 & 10 & 0.5 & $20>0$ & Cooling \\
\hline 115 & 120 & 01.5 & 02.0 & 05 & 0.5 & $10>0$ & Cooling \\
\hline 125 & 130 & 02.5 & 03.0 & 05 & 0.5 & $10>0$ & Cooling \\
\hline 135 & 135 & 06.0 & 07.0 & 0.0 & 1.0 & 00.0 & Inversion \\
\hline 130 & 128 & 08.0 & 08.5 & -02 & 0.5 & $-04<0$ & Heating \\
\hline 117 & 115 & 11.0 & 11.5 & -02 & 0.5 & $-04<0$ & Heating \\
\hline 100 & 090 & 13.0 & 14.0 & -10 & 1.0 & $-10<0$ & Heating \\
\hline
\end{tabular}

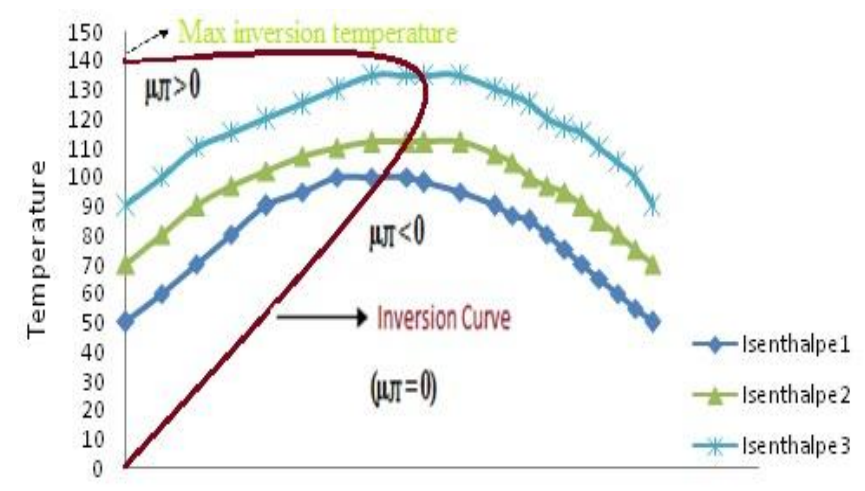

$\begin{array}{lllllllllllllllllll}0 & 1 & 2 & 3 & 4 & 5 & 6 & 7 & 8 & 9 & 10 & 11 & 12 & 13 & 14 & 15 & 16 & 17 & 18\end{array}$

Pressure

Fig 5: Joule-Kelvin Curve

For ideal condition from steady state energy equation :

$$
\begin{gathered}
d Q-d_{x}=d h+V . d v+g . d z \\
\Rightarrow d h+V . d v+g . d z=0
\end{gathered}
$$

here $\mathrm{dQ}=0$ ( due to insulation)

$$
\begin{gathered}
\Rightarrow d h=0 \\
\Rightarrow h_{2}-h_{1}=0 \\
\Rightarrow h_{1}=h_{2}
\end{gathered}
$$

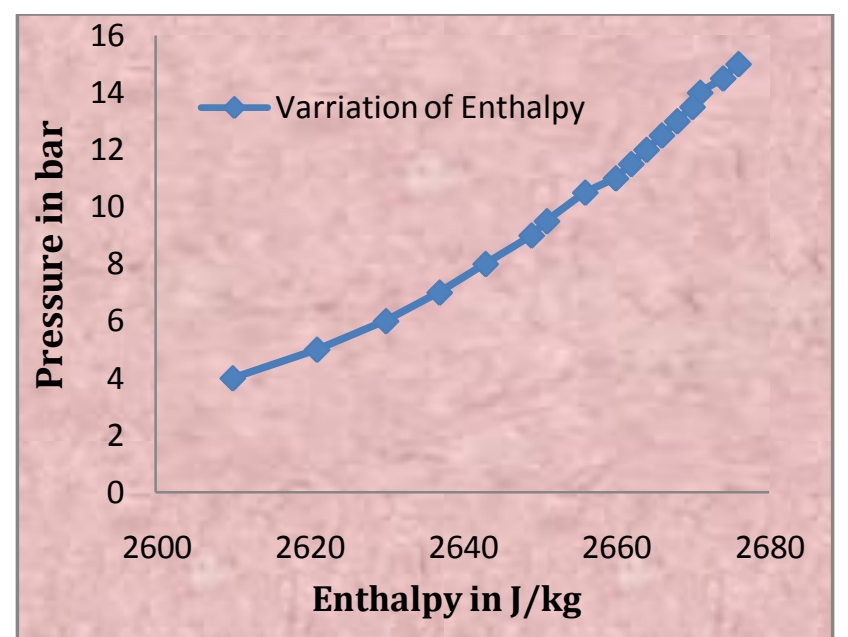

Fig 6: P-h Curve of water vapour

Each isenthalpe should carry constant enthalpy on each point on curve. Since there is irreversbility and heat dissippation towards surrounding. There is some variation in enthalpies at different points on isenthalpe's. If we draw the P-h curve for better understanding, there should ideally be a vertical line but actual line is not vertical due to irreversibility and heat dissipation.

\subsection{Analysis of P-T diagram}

After taking the readings of pressure and temperature with the experimental setup, P-T diagram can be drawn. As water is saturated vapour so these temperature and pressure are saturated temperature and saturated pressure. Hence formed P-T diagram shows only the line of vaporization of whole P$\mathrm{T}$ diagram. This shows that as temperature increases, pressure also increases with it. Real diagrams are at least similar to ideal diagram. 


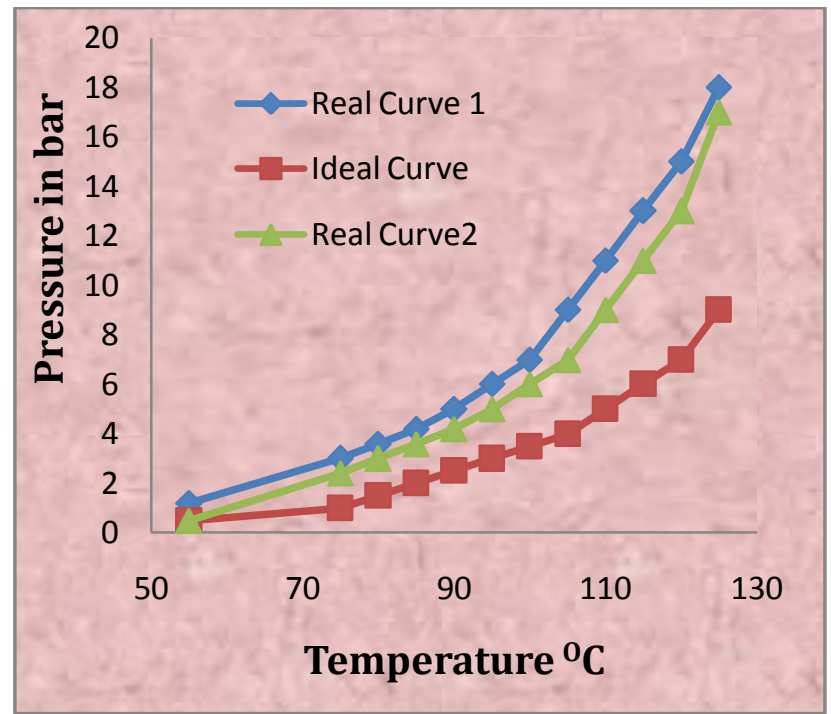

Fig 7: P-T diagram of water vapour

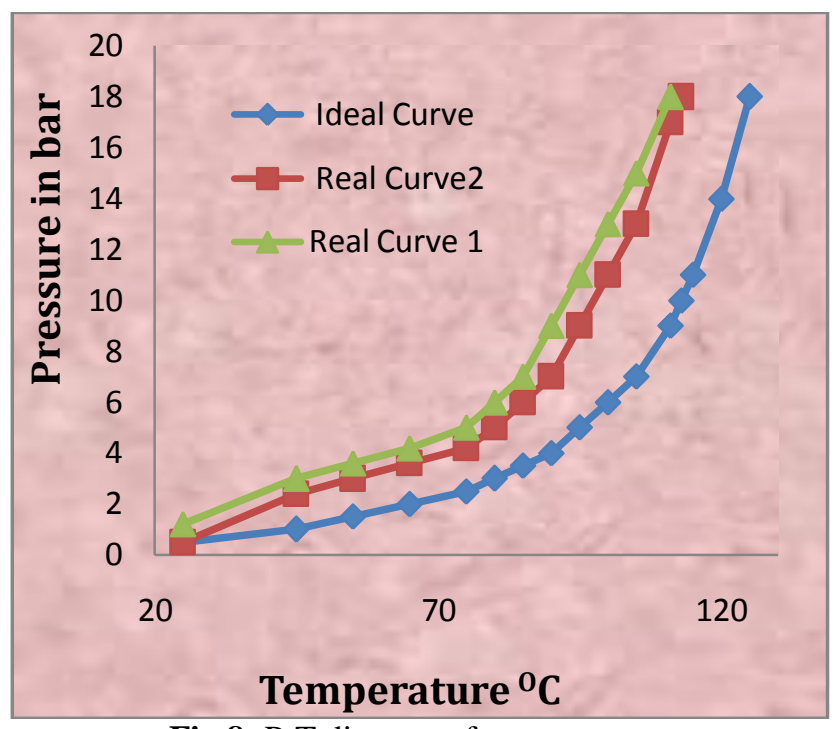

Fig 8: P-T diagram of water vapour

\subsection{Analysis of T-V Diagram}

To analyze and draw the T-V diagram, volume can be find by multipling the time in discharge that is in LPM. Volume is calculated for one minuts. $\mathrm{V}$ is more than volume of saturated liquid and less than volume of saturated vapour $\left(\mathrm{V}_{\mathrm{f}}<\mathrm{V}<\mathrm{V}_{\mathrm{g}}\right)$ so steam is saturated and so diagram shows the saturated vapour line of $\mathrm{T}-\mathrm{V}$ diagram. This diagram shows that the volume of discharge increases with the saturation temperature. To check the accuracy of setup and diagram, these diagrams are compared to the diagram drawn from data of standard steam table. The real curves are not exact but simillar to ideal curve.

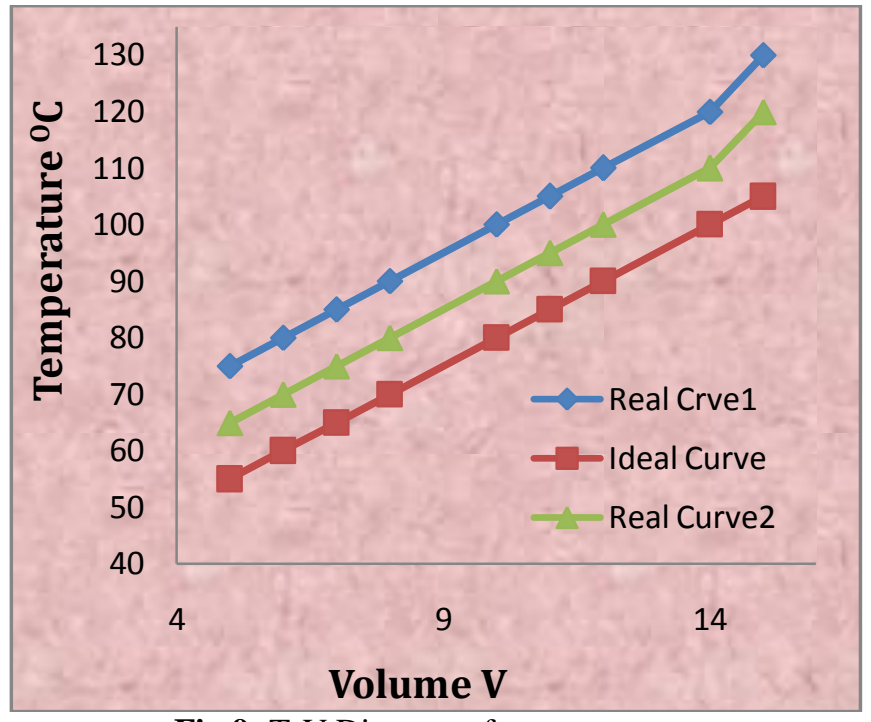

Fig 9: T-V Diagram of water vapour

\subsection{Analysis of P-V Diagram}

This diagram shows the saturated vapour line of water vapour. This diagram also shows that the volume of steam decreases as the saturation pressure increases. It is hyperbolic curve. To check the accuracy of setup and diagram, these diagrams are compared to the diagram drawn from data of standard steam table. Here also real diagrams are at least similar to ideal diagram.

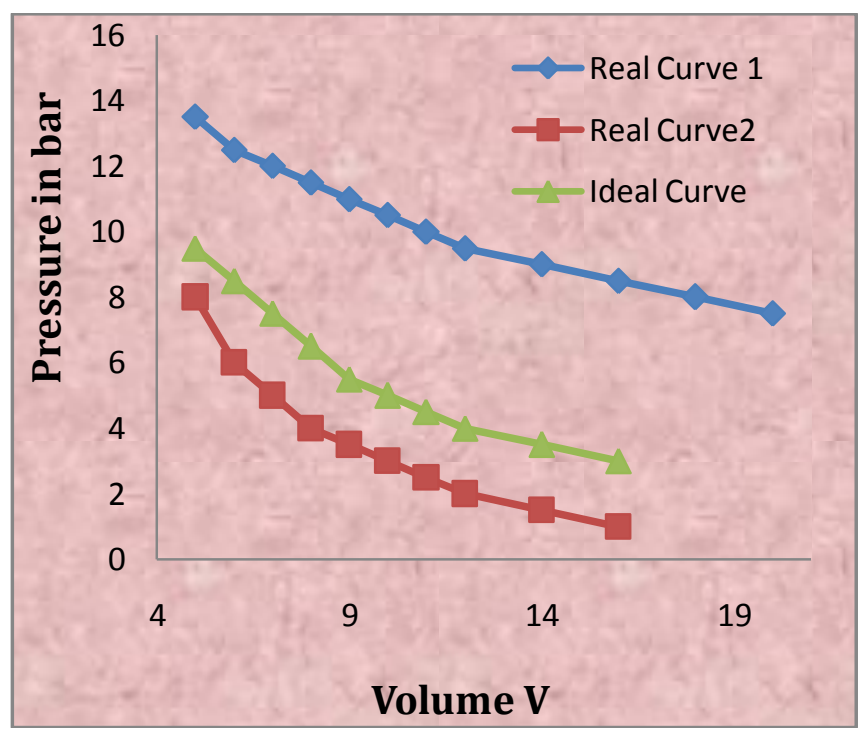

Fig 10: P-V Diagram of water vapour

\subsection{Analysis of Free Expansion Process}

Free expansion or unresisted expansion or Joule expansion is one in which fluid expands suddenly into a vacuum chamber through an orifice of large size. There is not vacuum in pressure cooker in which steam is expanded, but when we expandes the steam in empty pressure cooker suddenly, we observered same result as in ideal free expansion with vacuum chamber for a small time period. So we analyzed the free expansion with assumption that there is vacuum in pressure cooker for an instant. 
The final temperature of the steam is same as the initial temperature in steam generating pressure cooker. Though the expansion of steam through gateway valve causes fall in temperature, the friction converts the kinetic energy into heat which increases the temperature to the original temperature.

Table 5: Temperature observed in free expansion

\begin{tabular}{|c|c|c|}
\hline \multicolumn{3}{|c|}{ experiment } \\
\hline $\begin{array}{c}\mathbf{T}_{\text {Initial }} \\
\left(\mathbf{T}_{\mathbf{i}}{ }^{\mathbf{0}} \mathbf{C}\right)\end{array}$ & $\begin{array}{c}\mathbf{T}_{\text {Intermediate }} \\
\left(\mathbf{T}{ }^{\mathbf{0}} \mathbf{C}\right)\end{array}$ & $\begin{array}{c}\mathbf{T}_{\text {Final }} \\
\left(\mathbf{T}_{\mathbf{f}}{ }^{\mathbf{0}} \mathbf{C}\right)\end{array}$ \\
\hline 125 & 123.0 & 125 \\
\hline 123 & 121.5 & 123 \\
\hline 120 & 117.0 & 120 \\
\hline
\end{tabular}

This process is highly irreversible since the steam is eddying continuously during the process. As after generating the ample amount of steam, heat supply is stopped, then the free expansion in analyzed. In this process as no external heat has been supplied and no work has been done during the expansion process, there is no change in internal energy. The enthlpy of the steam remains constant during process. The non flow energy equation can be applied between the initial and final states.

$$
\begin{aligned}
& \mathbf{Q}=\mathbf{W}+\left(\mathbf{U}_{2}-\mathbf{U}_{1}\right) \\
& \Rightarrow\left(\mathbf{U}_{2}-\mathbf{U}_{1}\right)=\mathbf{0} \\
& \quad \Rightarrow \mathbf{m} \cdot \mathbf{C}_{\mathrm{v}} \cdot\left(\mathbf{T}_{2}-\mathbf{T}_{1}\right)=\mathbf{0} \\
& \quad \Rightarrow\left(\mathbf{T}_{2}-\mathbf{T}_{1}\right)=\mathbf{0} \\
& \quad \Rightarrow \mathbf{T}_{2}=\mathbf{T}_{1}
\end{aligned}
$$

The free differs from isothermal expansion in having no work transfer. For the same reason, it is not reversible adiabatic process. The free expansion is irreversible process and can not be truly represented on P-V diagram. It is represented by dotted line on $\mathrm{P}-\mathrm{V}$ diagram.

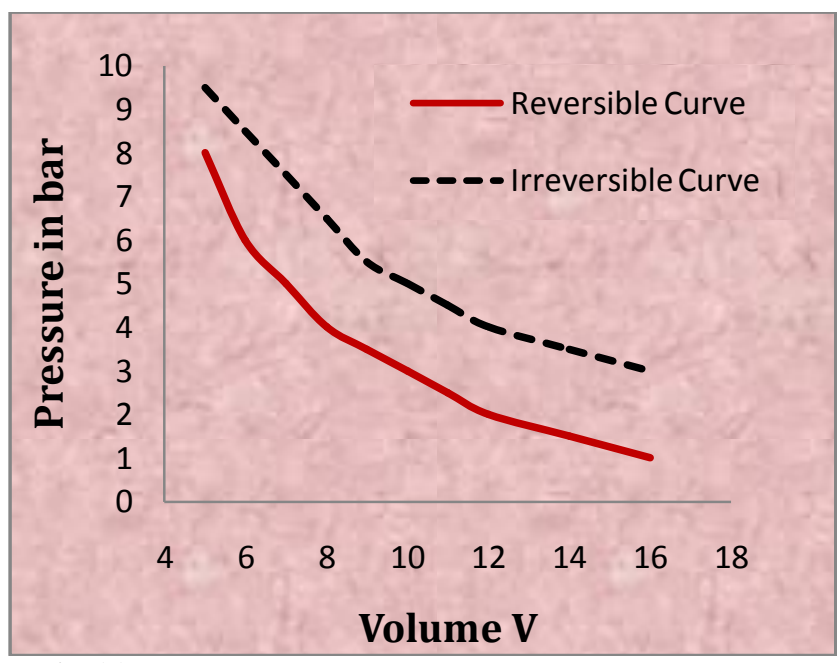

Fig 11: P-V Diagram showing reversible \& irreversible process

\subsection{Analysis of Dryness Fraction}

Dryness fraction or quality is the ratio of the mass of vapor to the total mass of mixture.

$$
\text { Dryness Fraction, } Q=\frac{m_{v}}{m_{t}}
$$

Where : $\mathrm{m}_{\mathrm{v}}=$ Mass of vapour

$$
\begin{aligned}
\mathrm{m}_{1} & =\text { Mass of liquid } \\
\mathrm{m}_{\mathrm{t}} & =\text { Total mass of mixture } \\
& =\mathrm{m}_{\mathrm{v}}+\mathrm{m}_{\mathrm{l}}
\end{aligned}
$$

But for calculating quality of steam at diffrerent point of pressure and temperature, calculation of entropy is easy because of online entropy calculator and then with help of steam table of saturation pressure, dryness fraction of steam can be calculated by using the formula which is enlisted in the table 6 .

Table 6: Dryness fraction with it's calculation

\begin{tabular}{|c|c|c|c|c|c|}
\hline $\begin{array}{c}\mathrm{P} \\
\text { bar }\end{array}$ & $\begin{array}{c}\mathrm{T} \\
{ }^{\mathrm{O}} \mathrm{C}\end{array}$ & $\begin{array}{c}\mathrm{S} \\
\mathrm{kJ} / \mathrm{kgK}\end{array}$ & $\begin{array}{c}\mathrm{S}_{\mathrm{f}} \\
\mathrm{kJ} / \mathrm{kgK}\end{array}$ & $\begin{array}{c}\mathrm{S}_{\mathrm{fg}} \\
\mathrm{kJ} / \mathrm{kgK}\end{array}$ & $\begin{array}{c}\mathrm{x}=(\mathrm{S} \\
- \\
\left.\mathrm{S}_{\mathrm{f}}\right) / \mathrm{S}_{\mathrm{fg}}\end{array}$ \\
\hline 15.0 & 050 & 7.347 & 1.307 & 6.048 & 0.9986 \\
\hline 14.5 & 055 & 7.358 & 1.303 & 6.057 & 0.9983 \\
\hline 14.0 & 060 & 7.371 & 1.287 & 6.091 & 0.9988 \\
\hline 13.5 & 065 & 7.382 & 1.276 & 6.115 & 0.9984 \\
\hline 13.0 & 070 & 7.395 & 1.270 & 6.125 & 0.9989 \\
\hline 12.5 & 075 & 7.408 & 1.252 & 6.163 & 0.9982 \\
\hline 12.0 & 080 & 7.422 & 1.245 & 6.182 & 0.9994 \\
\hline 11.5 & 085 & 7.436 & 1.230 & 6.202 & 0.9985 \\
\hline 10.5 & 090 & 7.467 & 1.201 & 6.270 & 0.9993 \\
\hline 8.5 & 098 & 7.539 & 1.135 & 6.409 & 0.9992 \\
\hline 8.0 & 100 & 7.559 & 1.125 & 6.431 & 0.9995 \\
\hline 7.0 & 105 & 7.604 & 1.079 & 6.530 & 0.9996 \\
\hline 6.0 & 110 & 7.657 & 1.035 & 6.560 & 0.9991 \\
\hline 3.0 & 080 & 7.895 & 0.980 & 6.747 & 0.9987 \\
\hline 2.0 & 070 & 8.036 & 0.737 & 7.296 & 0.9997 \\
\hline
\end{tabular}

\section{CONCLUSION}

Result of the experimental setup have explaneed and analyze the accuracy of this setup by comparing these results to corresponding data of standard books. Although all the curves have atleast similarty with ideal curve of standard books but there are many errors in these curves due to irreversibility, heat dissipation to surrounding and error during taking readings. After all these finally some of conclusion find out and those are:

1. The Joule-Kelvin Curve analyzed the Joule Kelvin effect, inversion curve and calculated the Joule-Kelvin coefficient for each isenthalpe.

2. The throttling process is prooved that it is isenthalpic process practically and mathematically.

3. Practical observation of free expansion process prooved that in this process initial and final temperature remain constant practically and drew a dotted curve which shows that it is an irreversible process.

4. The drawn P-T, P-V and T-V diagrams are analyzed practically and compared it to ideal diagrams and studied about the irreversibility of these diagrams.

5. Entropy of steam at different pressure and temperature dryness fraction of steam are calculated at each point. 


\section{REFERENCES}

[1] Yunus Ali Cengel \& Michael A. Boles, "Thermodynamics An Engineering Approach", Tata McGraw-Hill, New Delhi, $7^{\text {th }}$ edition, 2011.

[2] P K Nag, Engineering Thermodynamics, "Tata McGraw-Hill, New Delhi", $4^{\text {th }}$ edition, 2008.

[3] Ernest O Doebelin \& Dhanesh N Manik, Measurement System Application and Design, Tata McGraw-Hill, New Delhi, $5^{\text {th }}$ edition, 2007.

[4] R.S. Khurmi \& J.K.Gupta, A Textbook of Machine Design, S.Chand, New Delhi,2011.

[5] P N Rao, Manufacturing Technology Vol-1, Tata McGraw-Hill, New Delhi, $3^{\text {th }}$ edition, 2011.

[6] Shigley \& Mischke, Mechanical Engineering Design, Tata McGraw-Hill, New Delhi, $8^{\text {th }}$ edition, 2008.

[7] Mathur \& Mehta, Thermal Science and Engineering, Jain Brothers, New Delhi, 2002.

[8] D.M. Considine, Process Instruments and Controls Handbook, Tata McGraw-Hill, New York, $3^{\text {rd }}$ edition.

[9] R.W.Bradspies, Bourdon Tubes, Giannini Tech. Notes, Giannini Corp, Duarte, 1961.

[10] V.P.Head, Float-Type Variable-Area Flowmeters, Trans. ASME, August 1954.

[11] Guide to By-Pass Rotameter Application, Tech. Bull, Brooks Instrument. (www.brooksinstrument.com).

[12] R. Gitlin, How Temperature Effects Instrument Accuracy, Contr., April, May, June 1995.

[13] S.G. Eskin \& J.R. Fritze, Thermostat Bimetals, Trans. ASME, July 1940.

\section{BIOGRAPHIES}

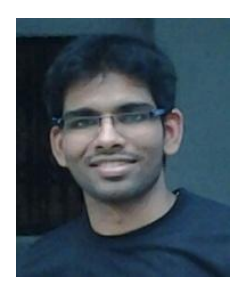

${ }^{1}$ Er. Rahul Patel is working as an Assistant Professor From $1^{\text {st }}$ January 2014 to till now in Mechanical Engineering Department, Chandra Shekhar Azad University of Agriculture and Technology, Etawah (Campus) - INDIA. He is Graduated, B.tech (Mechanical Engineering) Batch- 2013, from- Baba Saheb Dr Bhim Rao Ambedkar Collage of Agricultural Engineering and Technology Etawah- 206001. His area of interest is Thermal Engineering as well as Production Engineering, Specially Refrigeration and Air Conditioning. E-mail: rahul.patelworld@gmail.com, Contact No:- +919450800992

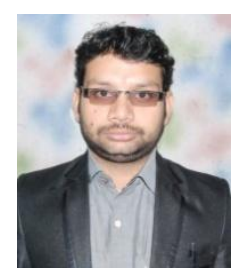

${ }^{2}$ Er. Ramji Tripathi is working as an Assistant Professor From $1^{\text {st }}$ January 2014 to till now in Mechanical Engineering Department, Chandra Shekhar Azad University of Agriculture and Technology, Etawah (Campus) - INDIA. $\mathrm{He}$ is Graduated, B.tech (Mechanical Engineering) Batch- 2013, from- Baba Saheb Dr. Bhim Rao Ambedkar Collage of Agricultural Engineering and Technology Etawah- 206001. His area of interest is Thermal Engineering. E-mail: mychemistry123@gmail.com, Contact No:- +917499246976

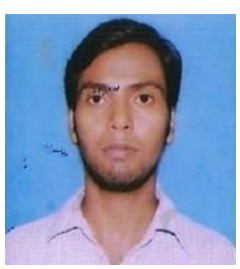

${ }^{3}$ Sukhdev Gangwar, Pursuing B.tech Degree in Mechanical Engineering from Baba Saheb Dr. Bhim Rao Ambedkar College of Agricultural Engineering \& Technology, Etawah U.P. Affilation:Chandra Shekhar Azad University of Agriculture And Technology Kanpur , Pin-206001. India, E-mail: dev.caet@ gmail.com, Contact No:- +919458659168. 12 $2^{\text {th }}$ Passout from Jawahar Navodaya Vidyalaya Pilibhit- U.P. 